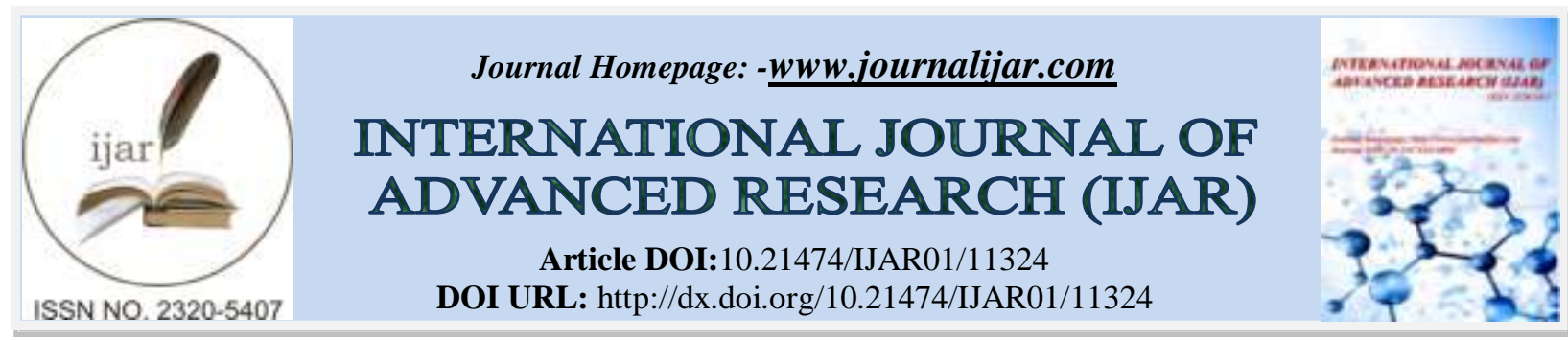

RESEARCH ARTICLE

\title{
UNSOLVABLE RELATIONSHIP BETWEEN ANATOMY AND HUMAN CADAVER: A BURDEN OR A BOON IN DISGUISE TO TEACH COMPENTENCIES IN MEDICAL CURRICULUM
}

\author{
Dr. Surajit Kundu ${ }^{1}$, Dr. Anil R. Sherke ${ }^{2}$, Dr. Jaideo M. Ughade ${ }^{3}$, Dr. Yogita Kanwar ${ }^{4}$, Dr. Ravikant Jatwar ${ }^{5}$, \\ Dr. Samta Tiwari ${ }^{6}$ and Dr. Richa Gurudiwan ${ }^{4}$ \\ 1. Associate Professor, Dept. of Anatomy, Late Shri Lakhiram Agrawal Memorial Govt. Medical Raigarh (CG) \\ India. \\ 2. Professor \& HOD. \\ 3. Professor (Govt. Medical College Nizamabad Telangana State). \\ 4. Assistant Professor. \\ 5. Demonstrator (Late Shri Lakhiram Agrawal Memorial Govt. Medical Raigarh CG State). \\ 6. Assistant Professor (Shri Ram Murti Smarak Institute of Medical Sciences, Bareilly, UP State).
}

\section{Manuscript Info}

(.........................

Manuscript History

Received: 10 May 2020

Final Accepted: 15 June 2020

Published: July 2020

Key words:-

Anatomy, Dissection, Education,

History, Cadaver

\section{Abstract}

The upcoming changes, trends and progress in medical science have probably modified the dissection of human cadaver in Anatomy teaching curriculum. The new computerized teaching aids are on the increase to capture the dissection hall and replace the hall from its beloved first medical teacher. We in this present manuscript try to put forth the various aspects of cadaveric human dissection from its inception including the bioethical aspects and opinions of published literature review. The traditional dissection tool as a teaching learning method of Anatomy should not be harassed and should be always considered as the most novel method of discussing human Anatomy for the medical fraternity. The current acute shortage of qualified Anatomy teaching faculty have been a challenge but may be adequately taken care by creating additional incentives, research grants and optimum encouragement for post graduate medical Anatomy teachers including doctoral fellows to teach and compensate for faculty who are aptly required for the upcoming next generation medical students.

Copy Right, IJAR, 2020,. All rights reserved.

\section{Introduction:-}

Anatomy has been widely acclaimed as one of the most important components of medical education. Further, the study of anatomy through the disserted cadaver is considered a unique defining feature of medical courses. But now we are about to enter a paradigm shift era with the help of a new perspective and new technology. Therefore, all temporary views are strongly held and emotionally expressed. Anatomy as a subject was very reasonable, banausic, archaic, and traditional. This is an obvious goal for new curriculum change because it has evolved and cannot adapt with changing time. Modern educators consider this to be important and full of unhelpful details. As a result, it does not mix as a modern, medically trimmed topic of $21^{\text {st }}$ century medicine. Moreover, the cadaver dissection was highly regarded as the "essence of anatomy" (1). 
Along with significant advances in technology, information and imaging tools, the resource for teaching anatomy has made a huge leap in education system. In this way, there are a huge number of instruments and methods, ranging from computer, to live body scan, as well as virtual three images, pro-section, plastic models, plastinated, and synthetic simulators that look as good as part of a real human being. These modern educational tools are clean, durable, odorless, hassle-free, and aesthetical in the sense that students do not need training. This is different from the traditional dissection session. This advancement in technology has gained many followers of the therapeutic education community. In the current educational context, anatomy has been polarized into two belief systems. Modernists who regard the separation of the dead as outdated and unnecessary, and traditional theorists believe that anatomy is the key to education. In order to work with the process of training and training future health professionals, this change in perceptions of teachers needs to be analyzed from a larger perspective who will one day face living patients.

Although the history of dissection has been well-studied, little attention has been paid to the use of living body in anatomy education. This study briefly reviews the historical perspective living anatomy. In addition, we discuss the value of individual dissection and executive use versus biometric and medical imaging studies. Finally, we consider future prospects: in the use of imaging and simulation techniques, in evaluating the educational method, and the use of art in supporting anatomical understanding ${ }^{(2)}$.

\section{Historical perspective of dissection:}

Cadaveric dissection has been the anatomy education as the Renaissance. Further, the significant experience of medical teaching after $16^{\text {th }}$ and $17^{\text {th }}$ centuries. Therefore, cadaveric dissection brings out often in medical education, even though regularly in semi-official and informal manner. The private anatomy schools have been created in conjunction with hospital-based specialized courses in the UK and elsewhere. However, "Royal College of Surgeons" decided not to take summer courses as qualifications for college diplomas in 1822. It began to disrupt the activities of private medical schools as well as the 1832 Anatomy Act strengthened this process. At the hospitalbased Anatomy School, there are strict rules for performing surgery, where the bodies of their deceased patients can be used (as a free treatment for stricter survival). This is a professional training model from an "apprenticeship model" of medical training (often limited to one-on-one instruction) to a large group of students where the primary purpose of teaching has shown a significant shift in education.

Along with that, a suitable distinction can be drawn among the observation of dissection (that was the mainstay of Renaissance teaching through the "Anatomy Theatre") as well as active dissection by the student themselves. In the United Kingdom, a method known as the "Paris Method" that gave each student their own executive responsibility. This is because students travel abroad as part of medical training. Step by step, dissection is considered a modern method and observation is associated with second class activities ${ }^{(3)}$.

On the other hand, more deep psychological changes may also have happened at present, when there was a change from the indeterminateness of traditional medicine ("folk medicine") to the professionalization and formalization of conventional medicine. This is the practice of treatment moved away from the idiosyncratic, personal as well as patient-focused opinion of the past to the standardized and diseased-focused world of the Rationalist future. In the late $18^{\text {th }}$ and early $19^{\text {th }}$ centuries in an uncertain medicine world, where in the past there was no rational or organized basis for treatment or diagnosis be present, it must have been the great well-being to turn to the body of anatomical knowledge. Moreover, it has been regular, consistent and able to shared and agreed thought by everyone working in the arena.

Besides that, the advance dissection can also strengthen by the rising sense of the formation of the professional monopoly. In the anatomy theater, the observation of dissection can be open to men and women, the medical practitioner and layperson as well. Meanwhile, dissection was not open to anyone as well as women were not allowed to attend in anatomy classes. In addition to growing medical skills in the early $19^{\text {th }}$ century went a separate masculinization $^{(4)}$.

Therefore, dissection has been encultured into the medical education that it has turn into an almost universal expectation of the courses of medical. In recent times, Dyer and Thorndike recommended that the status of anatomy as a science has declined because it is no longer measured to be a research-driven discipline. Moreover, there is a lot of debate about the nature of science. More general definition of science focuses on the formation of scientific hypotheses that can be denied or proved and modified by statements of conditional probabilities. Along with that, 
John Pickstone introduced a variety of views on the nature of science, recommending that technology, medicine, and science ought to be defined as the integrated enterprise of knowing and acting defined through four "ways of knowing": such as classifying and collecting data, extracting meaning, experimenting and analyzing. In this way, this is perhaps true that the previous anatomy originated their study of anatomy on a scientific data collection method (the direct opinion of body structure), which trailed by the hypothetical clarification as well as additional observational testing of hypothesis. Presumably, the primary disciplines established physical research on the scientific data collection method (direct observation of body structure), and this is probably true after more observational tests of hypothesis interpretation and hypothesis. Currently, without the field of neuroanatomy, it is impossible to discover new gross structures. In addition, this has contributed to the changed status of anatomy as a science. It looks that discipline, for example embryology and histology that originated from anatomy seem to have discounted it in terms of research context and popularity. Along with that, the anatomical body defined in the textbook is offered as objective reality. It is a series of simple observations inside the framework that are simultaneously easy to understand and complex enough for lifelong learning. This reality is one that everyone can study and evaluate as part of a general experience ${ }^{(5)}$.

\section{History of living Anatomy:}

In contradiction of the most written and documented history of anatomy teaching using the cadaver, and the history of teaching anatomy through biological research has been ignored to the best of our knowledge. A living body was certainly of great concern to artists and art history was able to provide access to the subject. In addition, Johann Zoffany says, "Dr. William Hunter was lecturing at the Royal Academy", near 1775. It shows the Hunter showing the rotation of the scapula on a living male model, where a sculpture and a skeletons representing the muscle group presented nearby. Along with that, Salle's painting "The anatomy class at the E'cole des Beaux Arts", showed in 1888, demonstrated the eminent anatomist, "Professor Mathias-Marie Duval", performing the demonstration on the living male model ahead of the class of student. The educator is holding the right arm of the model at the wrist as well as the upper arm in a somewhat unique position and looks to be blocking the basilica vein ${ }^{(6)}$.

The bones of the scapula and arm were identified as a unit, were in front of him at the table and were clearly used in the demonstration. Further, Duval was a physician and anatomist, and probably used "living anatomy" in medical education. However, some scholarly documents document the use of "living anatomy" is scarce. David Waterston was an anatomist, who revealed the Anatomy in the Living Model in 1931, where he mentioned: "It is now several years since the study of the living model was introduced into anatomy schools as a means of supplementing the training in anatomy obtained by the dissection of the cadaver". Furthermore, this recommended that it had not occurred before that time in UK medical school in any case. Accordingly, Waterson also mentioned the GMC ("General Medical Council") as having currently suggested that "the demonstration of structure and function in the living" ought to make a vital part of the professional training of medical students. But the GMC seems to have no record of this suggestion because of the incompleteness of their record. In 1947, RD Lockhart ("Regius Professor of Anatomy at Aberdeen") published Living anatomy that went into the second edition in 1949 and included appropriate advice: "Keep your eye on the body, especially the living body, is the first principle in anatomy". Besides, the photographic illustration, both female and male, are own students of the Lockhart, and there must be posed some movement at that time and place.

On the other hand, Barrows and colleagues proposed the use of life models in anatomy education, saying that "during the anatomy course, the students gradually develop an objective but respectful attitude towards the cadaver. Paradoxically medical students do not seem to enter the clinical arena with the same objectivity concerning the disrobed human body". Their study was quoted as the inspiration for the program of the living anatomy presented in 1978 by Stillman and colleagues at the "University Of Arizona College Of Medicine". They concluded that "live models were rated superior to using cadavers, especially in demonstrating superficial anatomy and landmarks". Both Stillman et al. and Barrows et al. favored the use of professional life model to the peer-examination. But on the contrary, in 1982 Metcalf and colleagues suggested the peer-examination that was more valuable than the use of the life model and presented the living anatomy course where obligatory peer-examination, such as breast and internal examination that was practice in the mixed sex pairing. Further, these authors and others refer to study as an introduction to a physical examination and the approach of studding anatomy per se. In addition, The "Anatomical Society of Great Britain" and the "American Association of Clinical Anatomist" are regularly repeating the need for structural identification in the living towards its "benchmark" core curriculum. But, trainings of anatomy teaching method often exclude the living anatomy as a research material ${ }^{(7)}$. 
Recently, attention has been focused on students' reactions to participating in the peer test. While these studies usually have reservations around certain sensitive areas of the body, they have determined that students are interested in participating in a peer exam. Moreover, various aspects such as ethnicity, age, body image, and religious background have proven useful for individual students. In this way, there are many important cultural issues in context to the participation in the peer-examination.

\section{Pros and cons of dissection: Advantages:}

Most published articles on anatomy education strongly recommend the use of dissection. Moreover, the proponent of dissection normally recognizes the many benefits that may spring from the dissection. Such benefits fall into three main areas, such as knowledge acquisition and integration, approach and skills. The benefits recognized in the first case include the development of cognitive anatomical knowledge as well as its specific vocabulary; establishing the system for tissue classification; appreciation of three-dimensional relationship and anatomical variability; and placing the grounds for the study of other self-restraints in which knowledge of structure is important (i.e. pharmacology, microbiology, and physiology); take part in cadaver or the patient-centered computer-aided learning and peer-group learning. Along with that, skill-based benefits contain developing fine motor control and the touchmediated insight of the patient or cadaver and developing ability in diagnostic imaging and training skills for the medical specialist. As a final point, attitudinal advantages together with establishing a patient mindset; promote professionalism through the direct counter with the cadaver as well as promoting arrogance favorable to team work. In recent times, medical students have expressed the appreciation for the historical implication of dissection as well as the development of admiration for the physical body as further causes to learn anatomy by dissection ${ }^{(8)}$.

\section{Disadvantage:}

Some believe that there are many important negative factors involved in the study of anatomy by dissection that again fall into three areas. Those relating to the emotional impact of dissection; the health and safety issues of the person who handles cadaveric material, and finally, the practicalities and the cost of using cadavers. Contrary to reports that dissection may endorse the considerate understanding of death, several studies have described dissection as a cause for extreme anxiety as well as the emotional vulnerability in some student, while, on the other hand, the levels of desensitization that can lead to unnecessary detachment from the death. Further, other have recommended that the cadaver has small clinical significance because of its appearance (texture and color), the lack of smell and mobility. Further, there are important health and safety implication essential to the use of cadavers that consist of experience to protecting fluid chemical and incorrectly stored human materials as well as the infective diseases, for example human immunodeficiency virus, transmissible spongiform encephalopathies, hepatitis and tuberculosis. Along with that, it associated with the Anatomy Act and the Human Tissues Act in UK.

There are also practical issues related to dissection, for example the difficulty in obtaining cadavers, disposing and maintaining of cadavers, the cost of transporting, the lack of qualified anatomists, and the time required to learn through dissection. In this way, the procurement of cadaveric materials is showing gradually difficult and sometimes fraught with tension. In 2001, there has been 10 percent reduction in number of bodies acknowledged by "Her Majesty's Inspector of Anatomy" (HMIA) for the anatomical study (from about 670 in 2001 to 600 in $2004 / 05$; personal communication, HMIA). In part, this is because of a reduction in the number of potential donors following health and safety guidelines that do not allow the acceptance of donors diagnosed with mild dementia ${ }^{(9)}$.

Public opinion on the anonymity has been blamed by recent scandals in Alderney and Bristol, and possibly by "Gunther Von Hagen's controversial Body Worlds Exhibition and public autopsy" and the public autopsy that received the mixed response from the common people. These factors have played a role in reducing the amount of cadaveric materials available for physical research, as well as increasing the number of students across the UK, together with the establishment of eight new medical schools, have each contributed to the reduction in the amount of cadaveric material accessible for the anatomical studies. The lack of cadavers leads to higher students. In addition, cadaver ratio must certainly deviate from the value of dissection as a suitable learning activity.

\section{Concept of emotional stress in Dissection curriculum:}

In addition to the increasing pressure to perform well, students also face the cadre for the first time and the emotional and emotional stress associated with the process of disconnection. Madill and Latchford assert that breaking the ban on human isolation led to a change of identity from layperson to treatment-to-be, and represents a sensitive episode for students. The stress of the isolation course may manifest itself in symptoms such as different 
types of sleep apnea, nausea or irritability, which in rare cases were compared with symptoms of traumatic stress syndrome. The most acutely sensitive responses to isolation occur before the initial contact with the donor organization and thus probably represent the expected phobic responses. In the past, many studies have proven that most students go through the process of adjusting to the first encounter, and their fears are significantly reduced.

During isolation, students are aware of the stress each time they work on the parts of the body that work intimately or the personality of the deceased, such as the mouth, hands, or still intact donor body. Fears and anxieties subside very quickly during the course, often making room for professional curiosity and a positive experience of the situation, while other stressors such as learning and examinations are increasing. Only a small percentage (4-6\%) of students suffers from chronic adjustment problems during the course. It can manifest itself in the form of nightmares, loss of appetite, insomnia or difficulty in learning and concentrating ${ }^{(10)}$.

Usually, students are re-aware of the role of the donor only after completing all the tests or courses. In the past, various methods have been described for how students handle this stress. Facing systems such as humor, intellectualization, scientific interest, and philosophical or religious attitudes are used. However, it has been shown that students need to guide the donor's image as a learning topic and as a unique and unforgettable human being. The purpose is to care for the donor - who can be seen in the figurative sense as the first patient of the future physician. And at the same time professional distance should be maintained. The concept of "caring for the body and yet not getting too close" has been described by Dickinson et al, 1997 as "detached concern". Montrose (2007) documented this concept by documenting his own experience in a lab in a laboratory: "We must learn not to be frozen in place by the sight of death; [...] we must begin to individually shape how we will cope with the impact of these extraordinary moments of urgency and whether these coping mechanisms take a healthy or unhealthy form". Along with that, this is the duty of anatomy educators to assist and support students in this process of balancing isolation and empathy, and to establish a common premise for moral anatomical education.

Previous studies hypothesize that treatment at the pre-clinical phase of the study may influence the prevalence of burnout among students, and this stress is negatively associated with sympathetic behavior. In short, it can be assumed that, if students fail to master the professionalism of "detached concern" or other appropriate coping strategies, there is a risk of resorting to inappropriate or incorrect strategies. This can lead to loss of future physician-patient relationships in the process of learning over time or in less sympathetic interactions with patients. Regardless of the true cause, chronic mental stress can promote anxiety, frustration or irritation. A state that, in addition to frustration, can promote not only drug and drug abuse, but also suicidal thoughts among medical students $^{(11)}$.

\section{An index of emotional stress:}

It is important to be able to identify students at an early stage who may be most likely having problems upon the first relation with cadaver or during dissection. The following indicators have already been identified, as follows:

Prior experience: In general, about half of medical students in Western countries have never seen a dead body before starting a separation. For this group, the first day of the course is particularly stressful and can lead to a very intense ordeal if there is a death in their family or close friends. The impact of previous treatment training or experience is less consistently evaluated across the board: On the one hand, students who do not have previous treatment training or prior experience need more emotional support and more time to develop adequate coping strategies, but no difference is noted to the opposite effect or absence.

Gender: Multiple studies have shown that female students feel emotionally more strongly affected than their male peers, especially before the onset of isolation. At this point, women worry more about their own mortality and for the first time fear the disintegration of a human body. One possible explanation for this gender-specific difference would probably be in different body-perceptions or awareness between the sexes. As a result, women adapt less quickly to isolated situations than men, and often yearn for a familiarity course ${ }^{(12)}$.

Personality: Purposeful steps (such as extraversion-intrusion, openness, consent, neuroscience, conscience), such as personality analysis by Big Five personality traits, are very time-consuming and expensive for regular use in a university setting. To date, no connection between subjective perceptions of emotional stress and student age, with their ethnicity or their degree program, has been clearly demonstrated. Accordingly, special attention should be paid 
to female students, students with no pre-treatment experience, and students facing personal death, especially at the beginning of the course.

However, it is important to note that emotional stress resulting from the initial conflict with the cadre can be seen as a difficulty in teaching anatomy and thus can be argued against the very source-demanding method of isolation, which continues to be the case with most anatomy faculty (69\%) as well as students as the best learning and teaching method.

Dissection Vs other educational tools (Advantages and disadvantages):

Technological Innovation and other resources built over the past 30 years have stimulated discussions in context to the role of dissection as an educational tool. Many different opinions on these topics can be classified into two perspectives. First, it claims that dissection is the best way to teach anatomy. There are several reasons why those who find the key to teaching anatomy of the deceased anatomy. Both are comparative studies of curriculum, both used by many institutions in the US, Europe, and Canada. Second, dissection is essential. However, studies matching the performance of cadaver dissection and multimedia programs in anatomy learning have shown that multimedia program for learning anatomy have produced result that often supports retentive dissection accompanied with the multimedia learning. As this concept developed, several medical universities have replaced traditional anatomy labs with computer labs and some broke down again. This discussion highlights the important changes in the medical education and the teaching anatomy ${ }^{(13)}$.

\section{Present situation of dissection (Imparting competencies through dissection):}

Dissection has been a primary learning tool for many years. These benefits include the acquisition of the practical skills, for example appreciation of the human body, a direct understanding of the anatomical variability, the learning of teamwork and peer interaction, and the ultimate realization of human life through direct understanding of death and death. But do all countries teach anatomy to anatomy? Data is available from universities in the Canada and United States, Russia and the United Kingdom. It found that different anatomy departments in Canada and United States and found that every school had some form of laboratory practice. In the United States, 96\% of reporting schools used dissection along with other tools, for example computer laboratories, bones, plastic model, and prosection $^{(14)}$.

Swamy and Searle reports that pro-section, dissection, and other anatomical factors were used in macroscopic education of the human gross anatomy. At the moment, there is no major study showing the general situation in the anatomy department of a Mexican medical school. Along with that, the "School of Medicine of the Autonomous University of Nuevo Leo' n" was established in 1859 with six teachers in charge of teaching each subject. The body anatomy program was implemented in 1940 and in 1976, the first integrated program of theory and practice was implemented. Besides, there are other resources such as bones, multimedia programs, and plastic models, but currently laboratory practice is mostly with dissection ${ }^{(15)}$.

\section{Shortage of qualified educators of Anatomy:}

In the past decades, institutions have applied various strategies to meet the shortage of faculty interested in teaching gross Anatomy. Also, these include training new faculty member (who usually hired on a research basis) to teach gross anatomy. Along with that, using part-time, non-tenured, and retired faculty member (including physician); training and holding their own graduate student as well as postdoctoral researcher to teach anatomy; Appointment of Physiological Anthropologists and hiring non-licensed physician from abroad. In most cases, these individuals do not contribute to research initiatives.

Inappropriately, in spite of their significant educational contributions, they are all often regarded as "second class citizens" of the academic community. Moreover, the best solution is to recruit new faculty members who have dynamic research activities, who are interested in and contribute to the teaching of gross anatomy. Further, the transition from post-doctoral members to junior faculty members seems to be key to encouraging them to teach overall anatomy, as these people have been trained, according to survey data. At the departmental level, the teaching load for educators of gross anatomy may be less educated, and reflection on microscopic anatomy and other faculty teaching in neuroscience can be reduced. These include collaborating with faculty who are active in studying course sections (e.g., head and neck, trunk, or limb) to provide anatomy courses taught by the team. It can be realized by creating ${ }^{(16)}$. 
At the institutional level, school management can provide financial support for that part of the post-doctoral associate's time for educational activities. This maintenance might counteract the loss of trained teachers that looks to take place during the postdoctoral ages. This is done for a small number of people in most institutions, but the huge investment in each school not only solves domestic problems, but also benefits the curriculum in the region. More highly trained teachers will remove "on the job" education and training at the junior teacher level. Research initiatives also benefit as a partial wage exemption from the support person and appoint additional postdoctoral associates. To give a concrete example, a postdoctoral colleague dedicates $25 \%$ of his physiological efforts to ensuring that his colleagues come from a management budget, not a grant from an epilepsy investigator. There may be discussion. Fellowship research experience may be somewhat modest each year but additional skill sets (guidance in anatomy) are provided to enhance employment opportunities. If four of these terms are discussed, the faculty will expand, the faculty will be reduced to faculty, and researchers will be able to appoint grants to compensate researchers for failure in the research program.

Another institutional strategy derives from the fact that many medical schools in the United States have established a "mission-based budgeting" format. Mission-based budgeting is the process of trying to allocate mission-specific income (such as education or state quotas) to potential teacher activities. (E.g., time spent in classroom and laboratory education) Teachers have the opportunity to allocate funds more specifically while engaging in timeconsuming activities such as Gross Anatomy. This directly addresses potential confusion in the teaching of anatomy ${ }^{(17)}$.

Finally, at the national level, problems can be resolved with assistance for Gross Anatomy training by restructuring NSH training grants. This solution was solved decades ago by a national problem. With the retirement of anatomists supporting NIH training grants in the 1960s, it's time to look at these solutions in the past and determine how they can be applied to current problems. If we do not want to solve this problem, surgeons, radiologists, physicians, nurses, dentists, physiotherapists, pharmacists, and others who primarily gain knowledge of human structures and functions from their trainers can create a generation of health professionals at human risk. People who come to learn today's anatomy lessons are taught. Along with that, increasingly sophisticated research and techniques are gathering to enhance the ability of diagnosis and treatment. We look forward to the future to ensure that those who develop and use these complex tools and medicines are taught with a deep knowledge and understanding of the human body.

\section{Discussion:-}

Even though the logic of dissection, those who claim to be anatomy or study anatomy separately often find that many anatomy departments around the world are the primary source of primary education. We employ a professional department. He asked for the change to restrict the use of increasingly scarce resources (i.e. cadavers and educational staff), to limit learning time and, above all, to improve test results and student outcomes in the long run. Thus, physiological teachers recognize that there can be no better way for students to acquire and retain physiological knowledge, a study that shows that long-term physical knowledge does not result in dissection.

The paybacks of learning anatomy through dissection are unacceptable to some students, especially those who tale that dissection allows psychological mapping of the three-dimensional internal structure of the body, but some other benefits are encouraged elsewhere in the medical curriculum. At present, some students visit patients in the first week of study, so cadaver are often not seen very often in the first patient, and are often found in a clinical setting that is available in a real patient or simulated clinical skills lab. We recommend meeting the best patients in the simulated environment of the clinical skill laboratory. In this way, the response of numerous medical schools means increasing teamwork skills and expanding the range of medical curriculum to promote understanding of death.

While it may be true that dissection allows the scientific methods to imitate the treatment diagnosis, the highest value of sequestration is when it is actively taught as a science of its level, and the highest value of the sequestration is in the process of self-discovery with education without being involved in the scientific method instead of inculcation of the scientific method. Along with that, evidence-based practice (EBP) and evidence-based medicine (EBM) which are integral components of many medical curricula may be more effective tools for promoting scientific methods ${ }^{(18)}$.

In a clinically appropriate environment where students can jostle, slice and navigate the body, the development of touch-mediated perception of physical and motor skills may also be encouraged. In fact, many students are not considered isolated enough to greatly develop this skill, given educated learners: some studies have reported the 
proportion of corpses. Historically, the main goal of the detachment and use of dead cadaver was the achievement of animals. However, in clinical practice, physicians are always required to work in vivo, and cadaver research is largely limited to different pathologists. Cadaver studies in chemical studies are rarely available in therapeutic practice. It is legitimate to ask if this primary purpose can be achieved better by another means of postgraduate medical courses.

The reaction of governments, students, and healthcare professionals to the suggestion that the dissection of humanitarian executives and the decline of research stored in medical education can dramatically decrease is one of sadness. In fact, the decision to adopt image processing in support of cadaver anatomy was usually a disadvantage for new medical schools' lifelong anatomy. The Times Medical School ran an article with history officials, a lack of training and placement in medical education, and a sharp commentary about a general practitioner: the key to dissecting the dead for centuries was an essential education aid ... as well as a passing program. ..But school students have a la show that is no different. Mentioning value in history is interesting because treatment practices generally focus on change and improvement. When discussing bleeding, equal use of conditions is essential. As well as a documentary series related to Professor von Hagens, the contents of the Channel 4 campaign have raised issues in the following terms: The interesting thing here is that the real anatomy is clearly identified with the dead, not the living body ${ }^{(19)}$.

At times discussions were poorly presented. For example, instead of discussing the value of living anatomy and imaging versus dissection, it is strongly suggested that all physiological education is conducted using plastic models. The motives can be misrepresented. For example, one reviewer wrote: Continue reading, and the decision to do so appears to be because of the cost and resources, but the authors of the original article, originally the physician who created the program, clearly indicate that it is involved in understanding anatomy in managing clinical problems. That is all you can do, and that doesn't mean executives do not necessarily include cheaper options. In fact, medical imaging and counseling are much more expensive than cadaver options that rely heavily on studying radiologists. The third technique is the general dissolution of a non-cadaveric approach that does not fit. Example: Educational fairness is not available.

In general, working with executives was sensitive to responding to suggestions that treatment might not be an integral part of training. Perhaps we can set a strong and sensitive point of view in the shift of the current parable. The nature of death, along with the cultural and physical challenges in managing and consolidating the dead human body, really helped propel the text used by the Times. These national events are usually uncomfortable and sometimes even painful, initially performing the task of connecting, but excluding those who have not gone through this process ${ }^{(20)}$.

More generalized anxiety reduces response. In addition, anatomist now assumes that subjects are at risk, with reduced resources and less skilled teachers. Communication away from dead body dissection can be interpreted as reducing the importance of anatomy as a component of therapeutic training. The human structure remains a very important part of the student's knowledge base. The question is rather what is physiological. However, knowledge of physiotherapy itself is not the goal of therapeutic education. Somewhat it has to be a good doctor.

\section{Conclusion:-}

In our opinion, dissection is an important tool in the Anatomy Lab and will continue to be. Dissection continues through many cultural changes, historical periods, and educational trends. In addition, it continues to evolve as new teaching strategies are added to the curriculum. Further, changes in society, culture as well as the medical curriculum have changed the environment, the trends and focus in teaching anatomy. Though, it is clear from above discussions, cadavers dissection in the lab remains a teaching tools. It will continue a basic method of learning anatomy. Moreover, history is a way of understanding the present and predicting the future. Further, understanding the history of dissection can help us understand their current role and anticipate future paths.

There is no standard or standard teaching tool for giving and recognizing the anatomical knowledge. Further, the purpose of this study is not to found one method over another, but to increase the benefits of learning from different methods. The value of the curriculum, how it is taught, how it is provided and the infrastructure provided, must be considered in the analysis of teaching and learning. Along with that, there is still no compelling evidence for the superiority of the changed curriculum compared to the traditional curriculum. New teaching methods in combination with core knowledge need to be re-evaluated in affection, not time and cost-effectiveness ${ }^{(21)}$. 
Then again, dissection has a well-established value in medical education and is reinforced by many students, physicians, physiologists, and the general community. Moreover, the dissected cadaver continue to be the most attractive way of presenting anatomy. Furthermore, this enables specialist to training safely and offers a dynamic basis for future clinical development. Along with that, the student-cadaver-patients encounter is dominant. Dissection has endured the challenges of the time and should not be blown away as old. The cadaver dissection and the latest technical resources presents diverse modes of learning anatomy. Several characteristic of all are important to develop theoretical, practical, and moral skills between students. In addition, computers can rise spatial knowledge as well as dissection can increase the vocabulary information. The complementary combination of the two variants can create the ideal situation for students as well as teachers to acquire anatomical knowledge and skills.

\section{Future Proposals:}

There is an ongoing debate about how to teach human anatomy in the most effective way, and there is still no practical integration of the two concepts to bridge the gap between the two approaches. We believe that cadaveric dissection and technical resources are represented by the necessary physical education and theoretical skills, as well as the various functionalities that develop some of each function. Students believe that they need to acquire skills and anatomical knowledge using both traditional and technical methods. Using traditional and technical resources, students need to develop skills that fall into three categories, namely bioethical, practical, and theoretical.

There is no uncertainty that a physician ought to have expertise in each of these three cases. Students learn clinical anatomy and integrate information on clinical cases (such as medical images, hyper facial anatomy and other necessary data) therefore they can recognize the physical basis of the case (technical resources). Moreover, students gain practical knowledge and skills by utilizing the instruments in the anatomy lab and by take part in primary surgical procedures on the cadaver (the traditional resource). Besides, the bioethical consideration arises from class discussion after and before the individual courses of dissection. In other words, dissection can also be used as an opportunity for self-directed and autonomous learning in which student groups can voluntarily separate at their convenient time instead of following to the restrictions on certain university schedules. Moreover, this new approach can help student overload and time limitations problems of modern medicine academia.

\section{Funding:}

No funding sources (Self funded).

\section{Conflict of interst:}

None declared.

\section{Ethical approval:}

Not required.

Sincere Acknowledgement: To Respected Dean Sir, HOD, all faculty and staff of Department of Anatomy and Medical education unit of Late Shri Lakhiram Agrawal Memorial Govt. Medical College Raigarh, CG India.

\section{References:-}

1. Ahmed, Kamran, Simon Rowland, Vanash Patel, Reenam S. Khan, Hutan Ashrafian, David Ceri Davies, Ara Darzi, Thanos Athanasiou, and Paraskevas A. Paraskeva. "Is the structure of anatomy curriculum adequate for safe medical practice?." The surgeon 8, no. 6 (2010): 318-324.

2. Azer, Samy A. "The place of surface anatomy in the medical literature and undergraduate anatomy textbooks." Anatomical sciences education 6, no. 6 (2013): 415-432.

3. Estai, Mohamed, and Stuart Bunt. "Best teaching practices in anatomy education: A critical review." Annals of Anatomy-Anatomischer Anzeiger 208 (2016): 151-157.

4. Finn, Gabrielle M., Marina Sawdon, and M. Griksaitis. "The additive effect of teaching undergraduate cardiac anatomy using cadavers and ultrasound echocardiography." European journal of anatomy. 16, no. 3 (2012): 199-205.

5. Franco, Nuno Henrique. "Animal experiments in biomedical research: a historical perspective." Animals 3 , no. 1 (2013): 238-273.

6. Ghosh, Sanjib Kumar. "Human cadaveric dissection: a historical account from ancient Greece to the modern era." Anatomy \& cell biology 48, no. 3 (2015): 153-169. 
7. Hulkower, Raphael. "From sacrilege to privilege: the tale of body procurement for anatomical dissection in the United States." Einstein Journal of Biology and Medicine 27, no. 1 (2016): 23-26.

8. Iancu, George, and Stergios K. Doumouchtsis. "A historical perspective and evolution of our knowledge on the cardinal ligament." Neurourology and urodynamics 33, no. 4 (2014): 380-386.

9. Jariyapong, Pitchanee, Chuchard Punsawad, Suchirat Bunratsami, and Paranyu Kongthong. "Body painting to promote self-active learning of hand anatomy for preclinical medical students." Medical education online 21, no. 1 (2016): 30833.

10. Jurjus, Rosalyn A., Kathryn Dimorier, Kirsten Brown, Frank Slaby, Hamid Shokoohi, Keith Boniface, and Yiju Teresa Liu. "Can anatomists teach living anatomy using ultrasound as a teaching tool?." Anatomical sciences education 7, no. 5 (2014): 340-349.

11. Kerby, Jane, Zena N. Shukur, and Joseph Shalhoub. "The relationships between learning outcomes and methods of teaching anatomy as perceived by medical students." Clinical Anatomy 24, no. 4 (2011): 489-497.

12. Moon, Karam, Andreas K. Filis, and Alan R. Cohen. "The birth and evolution of neuroscience through cadaveric dissection." Neurosurgery 67, no. 3 (2010): 799-810.

13. Mori, Shumpei, Tatsuya Nishii, Justin T. Tretter, Diane E. Spicer, Ken-ich Hirata, and Robert H. Anderson. "Demonstration of living anatomy clarifies the morphology of interatrial communications." Heart 104, no. 24 (2018): 2003-2009.

14. Mori, Shumpei, Diane E. Spicer, and Robert H. Anderson. "Revisiting the anatomy of the living heart." Circulation Journal (2015): CJ-15.

15. Pakhale, Sandeep V., Amrut A. Mahajan, Anita S. Fating, Shubhangi B. Ghule, and Bharat S. Borole. "Study of Student's Perception Regarding Increasing Objectivity during Practical Examination in Anatomy." International Journal of Health Sciences \& Research 2, no. 4 (2012): 48-53.

16. Pearce, Shane, Zoe Steinberg, and Scott Eggener. "Critical evaluation of modified templates and current trends in retroperitoneal lymph node dissection." Current urology reports 14, no. 5 (2013): 511-517.

17. Shoja, Mohammadali M., Brion Benninger, Paul Agutter, Marios Loukas, and R. Shane Tubbs. "A historical perspective: infection from cadaveric dissection from the 18th to 20th centuries." Clinical Anatomy 26, no. 2 (2013): 154-160.

18. Smither, Fantley, Anjali Bhagra, Nirusha Lachman, and Wojciech Pawlina. "The mini ultrasound institute: does incorporating ultrasound in the anatomy curriculum increase students' understanding of living anatomy and comfort with new technology?(211.4)." The FASEB Journal 28, no. 1_supplement (2014): 211-4.

19. Suzuki, Toru, Alessandro Distante, and Kim Eagle. "Biomarker-assisted diagnosis of acute aortic dissection: how far we have come and what to expect." Current opinion in cardiology 25, no. 6 (2010): 541-545.

20. Swamy, Meenakshi, and Roger F. Searle. "Anatomy teaching with portable ultrasound to medical students." BMC medical education 12, no. 1 (2012): 99.

21. Suzuki, Toru, Alessandro Distante, and Kim Eagle. "Biomarker-assisted diagnosis of acute aortic dissection: how far we have come and what to expect." Current opinion in cardiology 25, no. 6 (2010): 541-545. 